Pacific Journal of Mathematic 


\title{
ON MAPS WITH IDENTICAL FIXED POINT SETS
}

\author{
ROBERT F. BROWN
}

\begin{abstract}
If two maps on a space $X$, which admits a fixed point index, have identical sets of fixed points and agree on an open subset of $X$ which contains the fixed point set, then the maps have the same Lefschetz number. If the subset is closed, the conclusion is no longer true in general. However, a theorem of Leray implies that some kinds of maps on cartesian products of convexoid spaces which agree on a certain closed subset of their common fixed point set do have the same Lefschetz number, even though the maps may not be homotopic and may not agree on any open set containing the fixed point set. The purpose of this note is to prove a very general form of Leray's theorem for maps on ANR's.
\end{abstract}

Lemma. Let $X$ be a compact $A N R$, let $A$ be a closed subset of $X$, and let $f, g: X \rightarrow X$ be maps such that $f(a)=g(a)$ for all $a \in A$. Given $\gamma>0$, there exists an open subset $V$ of $X$ containing $A$ and a map $H: V \times I \rightarrow X$ such that $H(x, 0)=f(x), H(x, 1)=g(x)$ and

$$
d(f(x), H(x, t))<\gamma
$$

for all $x \in V, t \in I$, where $d$ denotes the metric of $X$.

Proof. Imbed $X$ in the Hilbert cube $I^{\infty}$, then there is a retraction $r: U \rightarrow X$ defined on some open subset $U$ of $I^{\infty}$ containing $X$. Let $d$ be the metric of $I^{\infty}$, then there exists $\eta>0$ such that

$$
X \subseteq \bar{N}(X, \eta) \subseteq U
$$

where $\bar{N}(X, \eta)=\left\{e \in I^{\infty} \mid \inf _{x \in X} d(e, x) \leqq \eta\right\}$. One can find $\delta>0$ such that $e_{1}, e_{2} \in \bar{N}(X, \eta)$ and $d\left(e_{1}, e_{2}\right)<\delta$ implies $d\left(r\left(e_{1}\right), r\left(e_{1}\right)\right)<\gamma$. Furthermore, there exists $\zeta>0$ such that if $x_{1}, x_{i} \in X$ and $d\left(x_{1}, x_{i}\right)<\zeta$, then $d\left(f\left(x_{1}\right), f\left(x_{2}\right)\right)$ and $d\left(g\left(x_{1}\right), g\left(x_{2}\right)\right)$ are both less than the smaller of $\delta / 2$ and $\eta$. Let $V=\left\{x \in X \mid \inf _{a \in A} d(x, a)<\zeta\right\}$ and define $H: V \times I \rightarrow X$ by $H(x, t)=r((1-t) f(x)+t g(x))$ for $x \in V, t \in I$.

For maps $f, g: X \rightarrow Y$ let $C(f, g)=\{x \in X \mid f(x)=g(x)\}$. Let $i$ denote the fixed point index for the category of compact ANR's [1]. For $U \subseteq X$, let $\partial U$ be the boundary of $U$ and $\bar{U}$ the closure of $U$.

Theorem. Let $\mathfrak{F}=(X, p, B)$ be a Hurewicz fibre space where $X$ and $B$ are compact ANR's. Given a map $f: X \rightarrow X$ and an open subset $U$ of $X$ such that $f(x) \neq x$ for all $x \in \partial U$, if $g: X \rightarrow X$ is a map such that $p g=p f$ and $C(p, p f) \cap \bar{U} \subseteq C(f, g)$, then 


$$
i(f, U)=i(g, U) .
$$

In particular, if $C(p, p f) \subseteq C(f, g)$, then $L(f)=L(g)$, where $L$ denotes the Lefschetz number.

Proof. We recall that since $B$ is an ANR, it is ULC, that is, there exists an open subset $W$ of $B \times B$ containing the diagonal and a map $\theta: W \rightarrow B^{I}$ such that for $b_{1}, b_{2} \in W$,

$$
\theta\left(b_{1}, b_{2}\right)(0)=b_{1}, \theta\left(b_{1}, b_{2}\right)(1)=b_{2},
$$

and $\theta(b, b)(t)=b$ for all $t \in I$. Let $d^{\prime}$ be the metric of $B$. There exists $\varepsilon>0$ such that $d^{\prime}\left(b_{1}, b_{2}\right)<\varepsilon$ implies $\left(b_{1}, b_{2}\right) \in W$. Furthermore, there exists $\gamma>0$ such that if $x_{1}, x_{2} \in X$ and $d\left(x_{1}, x_{2}\right)<\gamma$, then

$$
d^{\prime}\left(p\left(x_{1}\right), p\left(x_{2}\right)\right)<\varepsilon .
$$

Applying the lemma for $A=C(p, f p) \cap \bar{U}$ and this $\gamma$, we have an open subset $V$ of $X$ containing $A$ and a homotopy $H: V \times I \rightarrow X$. Let 0 be open in $X$ such that $A \subseteq \bar{O} \subseteq O \subseteq V$. Set $Q=U \cap O$ and consider

$$
H: \bar{Q} \times I \rightarrow X \text {. }
$$

There is a regular lifting function $\lambda$ for $\mathfrak{F}[3]$. Define $G_{1}: \bar{Q} \times I \rightarrow X$ by

$$
G_{1}(x, t)=\lambda\left[f(x), \theta_{t}^{\prime}(x)\right](1)
$$

where $\theta_{t}^{\prime}: \bar{Q} \rightarrow X^{I}$ is given by

$$
\theta_{t}^{\prime}(x)(s)=\theta(p H(x, s), p f(x))(t) .
$$

For the map $\tilde{\lambda}: X^{I} \rightarrow X^{I}$ defined by $\tilde{\lambda}(\alpha)=\lambda[\alpha(0), p \alpha]$, there is a homotopy $K: X^{I} \times I \rightarrow X^{I}$ such that

$$
K(\alpha, 0)=\alpha, K(\alpha, 1)=\bar{\lambda}(\alpha), p K(\alpha, s)(t)=p \alpha(t)
$$

for all $\alpha \in X^{I}, t \in I$, and if $\alpha$ is a constant path then $K(\alpha, t)=\alpha$ for all $t \in I$ [2, Proposition 1]. Define $G_{2}: \bar{Q} \times I \rightarrow X$ by

$$
G_{2}(x, t)=K\left(H^{\prime}(x), t\right)(1)
$$

where $H^{\prime}: \bar{Q} \rightarrow X^{I}$ is induced by $H$. Finally, consider $G: \bar{Q} \times I \rightarrow X$ where

$$
G(x, t)= \begin{cases}G_{1}(x, 1-2 t) & \text { if } 0 \leqq t \leqq 1 / 2 \\ G_{2}(x, 2-2 t) & \text { if } 1 / 2 \leqq t \leqq 1\end{cases}
$$

then $G(x, 0)=f(x), G(x, 1)=g(x)$ and $p G(x, t)=p f(x)$ for all $t \in I$. If $x \in \partial Q$ and $x \notin A$, then $p(x) \neq p f(x)$ so $x \neq G(x, t)$ for all $t \in I$. If 


$$
x \in \partial Q \cap A,
$$

then $f(x)=g(x)$ and by construction $H(x, t)=f(x)$ for all $t \in I$ so by the properties of $\theta$ and $K, G(x, t)=f(x)$ for all $t \in I$. Since $\partial O \cap A=\dot{\phi}$ and $\partial Q \subseteq \partial U \cup \partial O$, then $x \in \partial U$ so $f(x) \neq x$ by hypothesis which implies $G(x, t) \neq x$. Hence, by the homotopy axiom of the fixed point index [1], $i(f, Q)=i(g, Q)$. If $x \in \partial U$, then $f(x) \neq x$ and $g(x) \neq x$ while if $x \in U$ and $f(x)=x=g(x)$ then $x \in A \cap U \subset Q$. Therefore $f$ and $g$ have no fixed points on $\bar{U}-\bar{Q}$ and by the additivity axiom,

$$
i(f, U)=i(g, U) \text {. }
$$

The last sentence of the theorem follows by taking $U=X$ and using the normalization axiom: $i(f, X)=L(f)$.

As a special case, we obtain the result which Leray proved for convexoid spaces [4, Theorem 26].

Corollary. Let $X$ and $Y$ be compact ANR's. Maps

$$
f: X \times Y \rightarrow X, g: X \times Y \rightarrow Y
$$

induce $f \times g: X \times Y \rightarrow X \times Y$ defined by

$$
(f \times g)(x, y)=(f(x, y), g(x, y)) .
$$

Suppose $U$ is an open subset of $X \times Y$ such that $f \times g$ has no fixed points on $\partial U$. If $h: X \times Y \rightarrow Y$ is a map with the property that $(x, y) \in \bar{U}$ and $f(x, y)=x$ implies $h(x, y)=g(x, y)$, then

$$
i(f \times h, U)=i(f \times g, U) .
$$

Proof. The maps $f \times g$ and $f \times h$ satisfy the hypotheses of the theorem with respect to the trivial fibration of $X \times Y$ over $X$.

\section{REFERENCES}

1. F. Browder, On the fixed point index for continuous mappings of locally connected spaces, Summa Brasil. Math. 4 (1960), 253-293.

2. E. Fadell, On fibre spaces, Trans. Amer. Math. Soc. 90 (1959), 1-14.

3. W. Hurewicz, On the concept of a fibre space, Proc. Nat. Acad. Sci. U.S.A. 41 (1955), 956-961.

4. J. Leray, Sur les équations et les transformations, J. Math. Pures Appl. (9 me Série) 24 (1945), 201-248.

Reiceved March 4, 1966. This research was supported in part by the National Science Foundation Grant GP-4018.

UNIVERSity of CALIFornia, LOS ANGeleS 



\section{PACIFIC JOURNAL OF MATHEMATICS}

\section{EDITORS}

H. SAMELSON

Stanford University

Stanford, California

J. P. JANS

University of Washington

Seattle, Washington 98105

\section{J. DugunduI}

University of Southern California Los Angeles, California 90007

RICHARD ARENS

University of California

Los Angeles, California 90024

\section{ASSOCIATE EDITORS}
E. F. BECKENBACH
B. H. NEUMANN
F. WOLF
K. YoSIDA

\section{SUPPORTING INSTITUTIONS}

\author{
UNIVERSITY OF BRITISH COLUMRIA \\ CALIFORNIA INSTITUTE OF TECHNOLOGY \\ UNIVERSITY OF CALIFORNIA \\ MONTANA STATE UNIVERSITY \\ UNIVERSITY OF NEVADA \\ NEW MEXICO STATE UNIVERSITY \\ OREGON STATE UNIVERSITY \\ UNIVERSITY OF OREGON \\ OSAKA UNIVERSITY \\ UNIVERSITY OF SOUTHERN CALIFORNIA
}

\author{
STANFORD UNIVERSITY \\ UNIVERSITY OF TOKYO \\ UNIVERSITY OF UTAH \\ WASHINGTON STATE UNIVERSITY \\ UNIVERSITY OF WASHINGTON \\ AMERICAN MATHEMATICAL SOCIETY \\ CHEVRON RESEARCH CORPORATION \\ TRW SYSTEMS \\ NAVAL ORDNANCE TEST STATION
}

Mathematical papers intended for publication in the Pacific Journal of Mathematics should be typewritten (double spaced). The first paragraph or two must be capable of being used separately as a synopsis of the entire paper. It should not contain references to the bibliography. Manuscripts may be sent to any one of the four editors. All other communications to the editors should be addressed to the managing editor, Richard Arens at the University of California, Los Angeles, California 90024 .

50 reprints per author of each article are furnished free of charge; additional copies may be obtained at cost in multiples of 50 .

The Pacific Journal of Mathematics is published monthly. Effective with Volume 16 the price per volume (3 numbers) is $\$ 8.00$; single issues, $\$ 3.00$. Special price for current issues to individual faculty members of supporting institutions and to individual members of the American Mathematical Society: $\$ 4.00$ per volume; single issues $\$ 1.50$. Back numbers are available.

Subscriptions, orders for back numbers, and changes of address should be sent to Pacific Journal of Mathematics, 103 Highland Boulevard, Berkeley 8, California.

Printed at Kokusai Bunken Insatsusha (International Academic Printing Co., Ltd.), No. 6, 2-chome, Fujimi-cho, Chiyoda-ku, Tokyo, Japan.

\section{PUBLISHED BY PACIFIC JOURNAL OF MATHEMATICS, A NON-PROFIT CORPORATION}

The Supporting Institutions listed above contribute to the cost of publication of this Journal, but they are not owners or publishers and have no responsibility for its content or policies. 


\section{Pacific Journal of Mathematics}

\section{Vol. 21, No. 2 December, 1967}

Arne P. Baartz, The measure algebra of a locally compact semigroup ..... 199

Robert F. Brown, On maps with identical fixed point sets............. 215

C. Buttin, Existence of a homotopy operator for Spencer's sequence in the analytic case ..................................... 219

Henry Werner Davis, An elementary proof that Haar measurable almost periodic functions are continuous ........................ 241

Zeev Ditzian, On asymptotic estimates for kernels of convolution transforms ...................................... 249

Robert E. Edwards, Boundedness principles and Fourier theory ......... 255

John A. Hildebrant, On compact unithetic semigroups ............... 265

Marinus A. Kaashoek and David Clark Lay, On operators whose Fredholm set is the complex plane ............................ 275

Sadao Kató, Canonical domains in several complex variables ........... 279

David Clifford Kay, The ptolemaic inequality in Hilbert geometries.... . . . 293

Joseph D. E. Konhauser, Biorthogonal polynomials suggested by the Laguerre polynomials ............................. 303

Kevin Mor McCrimmon, Macdonald's theorem with inverses .......... 315

Harry Eldon Pickett, Homomorphisms and subalgebras of multialgebras .................................... 327

Richard Dennis Sinkhorn and Paul Joseph Knopp, Concerning nonnegative matrices and doubly stochastic matrices ..............

Erling Stormer, On anti-automorphisms of von Neumann algebras ...

Miyuki Yamada, Regular semi-groups whose idempotents satisfy permutation identities .......................... 